\title{
Effects of Postural Education and Physical Activity on UCLA Evaluation and Health Status in Adults from Chile: An Intervention Program
}

\author{
Félix Zurita-Ortega ${ }^{1}$ (D), Ramón Chacón-Cuberos ${ }^{2, * \mathbb{C}}$, Manuel Fernández-Sánchez ${ }^{3}$, \\ Cristian Cofre-Bolados ${ }^{4}$, María Concepción Navarro-Zurita ${ }^{5}$ and Manuel Castro-Sánchez ${ }^{1}$ (D) \\ 1 Department of Didactics of Musical, Plastic and Corporal Expression, University of Granada, 18071 Granada, \\ Spain; felixzo@ugr.es (F.Z.-O.); manuelcs@ugr.es (M.C.-S.) \\ 2 Department of Education, University of Almería, 04120 Almería, Spain \\ 3 Department of Nursing, Physiotherapy and Medicine, University of Almería, 04120 Almería, Spain; \\ manuelf@ual.es \\ 4 School of Sciences of Physical Activity, Sport and Health ECIADES, University of Santiago of Chile, \\ Santiago de Chile 9170022, Chile; cristian.cofre@usach.cl \\ 5 Research Group HUM-238, University of Granada, 18071 Granada, Spain; cnvzurita@yahoo.es \\ * Correspondence: rchacon@ual.es; Tel.: +34-958-248-949
}

Received: 2 November 2018; Accepted: 18 December 2018; Published: 20 December 2018

\begin{abstract}
Shoulder pathologies among the adult population are increasing, causing a high concern in health-educational institutions. The aim of this research is to take a step further and to conduct a detailed study of the relationship between the application of Jackins technique and a postural education program for people affected by shoulder problems. This quasi-experimental study was carried out on 41 adults with shoulder pathologies, with an average age of $58.17 \pm 11.75$. The main instruments used were the UCLA Test, Thermometer Euroqol of Health, and an ad-hoc questionnaire. In addition, SPSS 22.0 was used for statistical analysis. The results show that the Jackins shoulder rehabilitation program produces significant improvements in participants who it was applied to, causing a positive increase in shoulder evaluation and health status. Similarly, participants who were given a postural education treatment did not experience any modification in these variables. The Jackins program resulted in improvements in reference to shoulder evaluation. Thus, the course of the intervention program based on physical activity (six months) produces functional improvements in shoulder pathology through supervised therapeutic exercises and home intervention in patients with subacromial syndrome.
\end{abstract}

Keywords: subacromial syndrome; Jackins technique; postural reeducation; physical exercise

\section{Introduction}

The study of shoulder pathology and the disabilities caused by its alteration is a contemporary issue in the health and educational context. Frau-Escales et al. [1] revealed that $15 \%$ of adults 40-49 years old have pathologies associated with a painful shoulder. In fact, this percentage increases to $25 \%$ for the age range of 50-59 years. Specifically, Cadogan et al. [2] stated that the most common pathologies are those linked to the rotator cuff, followed by problems associated with the subacromial bursa and those related to the long head of the bicep tendon. This is reflected by several studies that indicate the importance of preventing and acting upon the occurrence of these types of pathologies in adulthood [3,4], particularly those affected by subacromial syndrome. This pathology refers primarily to the pain localized in the anterior region of the shoulder and its close relationship with the combined flexion-abduction movements [5]. 
Many detection techniques are used to identify shoulder disorders, some of which are invasive and others which are not. The concern is the nearness detection of pathology in order to avoid surgery and disability [6,7]. The most common noninvasive diagnostic technique is the use of X-rays, although diagnostic examination is also used to identify localized pain, calcifications, or fractures [2,7]. It is important to consider that the shoulder is the most unstable joint in the human body, which highlights the importance of receiving an early diagnosis and treatment of shoulder irregularities to avoid future surgeries [7-9]. This would involve a long process of rehabilitation and higher economic costs at the sanitary level. Therefore, it is important to carry out preventive actions through postural education.

Regarding these abnormalities or alterations, several studies show that injuries are often most frequent in certain professional groups whose work involves movements associated with abduction of the shoulder or lifting weights above the head, such as hairdressers, mechanics, gardeners, and agricultural workers $[10,11]$. Other studies indicate the negative effects of the realization of physical exercises that require gestures above the head with high loads or intensities, including basketball, volleyball, tennis, paddle tennis, sports gymnasiums, and other activities [11]. These types of movements require a large range of movement, which can generate injuries when people do not have a good execution technique [11,12].

Some studies show that therapeutic programs based on physical activity and postural education in the treatment of subacromial syndrome are associated with clinical effects in pain reduction, producing improvements in shoulder functionality and global health status [13-15]. Similar results had been obtained in the research developed by $\mathrm{O}^{\prime}$ Kane et al. [16], who applied the Jackins program in a population with capsular shoulder stiffness, resulting in a statistically significant improvement in the overall health status of patients, considering physical fitness, social function, and body wellness [17]. Moreover, Navarro-Zurita [18] reveals how this technique, which is based on low-intensity aerobic exercise, joint mobility, and exercises with moderate loads, produces a strengthening of the shoulder muscles that decreases instability and helps to reduce the prevalence of these pathologies.

The Jackins program is based on a set of tips and exercises, which have the purpose of encouraging nonsurgical treatment of the subacromial syndrome [16]. This is based on five phases. The first phase is a postural education for the modification of daily activities in order to avoid repetitive injuries. Subsequently, phase two focuses on the restoration of the normal flexibility of the shoulder joint without pain, while phase three is aimed toward recovery of muscle power through physical exercise with charges. Aerobic exercises are included to recover the physical fitness in phase four. Finally, work or sport modifications are included as preventive measures for avoiding relapses in phase five [16-19].

It is evident that this technique produces improvements in the evolution of subacromial syndrome based on the strengthening of the rotator cuff and the shoulder girdle, as well as an improvement of the flexibility of the soft tissues in the anterior and posterior areas of the shoulder. This suggests that the cycle of therapeutic exercises is recommendable as a conservative treatment, even before surgical treatment, to reduce symptoms and improve function [20]. Specifically, Ludewig et al. [21] demonstrated the benefits of practicing physical exercise for the improvement of shoulder pain and its functional status, as well as satisfaction levels related to the symptomatology of the injury. Therefore, the intervention through physical activity (Jackins program) and the development of adequate postural habits could be an effective method for the solution of these pathologies and to avoid future recurrence [22].

In line with all the above, Pepe et al. [23] and Christiansen et al. [24] emphasize the need of practice these exercises in the subacromial impingement of athletes, since they produce a strengthening of the subscapularis, infraspinatus, and teres minor, which are the rotator cuff muscles. In addition, they produce a decline in the humeral head, leaving more space under the coracoacromial arc, decreasing shoulder pain and perceived health status. In addition, the development of this musculature can act as a preventive measure against unadjusted movements for the joint [18].

It should not be forgotten that physical education teachers, doctors, and physiotherapists have the most responsibility in knowing how early to screen for and detect any performed abnormality. 
This research aims to take a step further by studying the effect of an implementation based on postural re-education and physical activity (Jackins program) in adults. Thus, the following research questions are stated in order to promote actions linked to prevent and treat shoulder pathologies in adults: Could an intervention program based on physical activity and postural education improve the UCLA evaluation of shoulder and the health status in adults? What action will be more effective in the treatment of shoulder pathology: Postural education, physical activity, or a combination of both?

Following the problems raised and the need to act before them, these hypotheses are proposed in relation to the intervention program developed:

Hypothesis 1 (H1): The different intervention programs (physical activity, postural education, and the combination of both) will improve the evaluation of the shoulder and the perceived health state.

Hypothesis 2 (H2): The combination of both programs will be the most effective for the improvement of shoulder pathology and health status.

Therefore, the aim of this study is to analyze whether the Jackins application program and an educational program improve the UCLA evaluation of shoulder and health status in subjects with shoulder pathology.

\section{Materials and Methods}

\subsection{Subjects and Design}

This is a longitudinal and quasi-experimental study. A total of 51 subjects who went daily to the association of Young Christians of Santiago of Chile (Chile) were selected. Inclusion criteria involved consideration of a medical diagnosis that revealed a shoulder pathology, an age range of 45-65, and possession of a cognitive state that allowed fluid communication. Exclusion criteria involved refusal to accept informed consent and the suffering of other disabling pathologies. These criteria were used to develop the intervention program. Finally, 41 adults aged 50-65 (58.17 \pm 11.75$)$ participated in this research, while 10 left the intervention program during its implementation. Of the remaining 41 subjects, 19 (46.3\%) were men, and 22 (53.7\%) were women. This sample is not considered representative for the adults from Santiago of Chile (Chile). Nevertheless, a sample error of 0.05 is assumed, considering the total population of adults that belonged to the Association of Youth Christians of Santiago de Chile $(n=156)$. A simple random sampling was carried out in order to assign different participants to the control group and the three experimental groups. The control group consisted of 11 subjects $(26.8 \%)$, while the three experimental groups each consisted of 10 subjects (24.4\%).

\subsection{Measures}

Several validated instruments were used to assess shoulder pathology and health status:

"Shoulder Rating Scale-UCLA." This instrument proceeds the original version proposed by Amstutz et al. [25] at the University of Los Angeles. This scale has been used worldwide and is the most globally recognized valuation element. It classifies shoulders using a scoring system, which establishes five evaluation elements based on pain, function, active flexion, muscle strength in active flexion, and satisfaction. The sum of each of the categories is calculated, establishing an overall score which determines shoulder assessment: excellent (34-35 points), good (28-33 points), regular (21-27 points), and bad (0-20 points).

"Visual scale thermometer EUROQOL of self-reported health." This test consists of a visual scale and a second part of the EQ-5D, formed by a vertical EVA scale of $20 \mathrm{~cm}$, ranging from 0 (worst state of imaginable health) to 100 (best state of imaginable health) [26]. In this scale, the individual must point to the mark on the vertical line that best reflects the assessment of their current overall health status. The use of EVA provides a complementary score to the descriptive system of a self-assessment of the individual's health status. 
"Sociodemographic Questionnaire." This instrument was used in order to register the age, sex, and pathology present (tendinopathy of the rotator cuff, tendon rupture, bursitis, frozen shoulder subacromial impingement, and rotator cuff), according to Navarro-Zurita [18] categorization.

\subsection{Procedures}

The collaboration of the rehabilitation centers from Santiago of Chile (Chile) was solicited to participate in the research, exposing to them the purpose of the study and requesting the cooperation of patients. Furthermore, a model of informed consent was attached and approved by the Ethics Committee. Four groups were created randomly (one control group and three experimental groups). Participants signed the free and informed consent term.

The intervention program consisted of three programs, which were administered to 41 participants. Two sessions per week during six months were performed. The Jackins program was performed three times a week for Group 1 and Group 2, while the educational program was implemented through workshops once a month (six sessions of $2 \mathrm{~h}$ ) to Groups 1 and 3 (Table 1).

Table 1. Treatments developed in different groups.

\begin{tabular}{ccccc}
\hline Groups & Group 0 & Group 1 & Group 2 & Group 3 \\
\hline Treatments & $\begin{array}{c}\text { Control Group } \\
\text { (No treatment) }\end{array}$ & $\begin{array}{c}\text { Jackins technique }+ \\
\text { Postural education }\end{array}$ & Jackins technique & Postural education \\
\hline Subjects & $\mathrm{n}=11(26.8 \%)$ & $\mathrm{n}=10(24.4 \%)$ & $\mathrm{n}=10(24.4 \%)$ & $\mathrm{n}=10(24.4 \%)$ \\
\hline
\end{tabular}

The development of the Jackins program applied to Groups 1 and 2 consisted of exercises aimed toward the recovery of shoulder pathology. This program follows the contributions of $\mathrm{O}^{\prime} \mathrm{kane}$ et al. [16], who established a five-phase treatment based on the different positions of the shoulder and the direct relationship between the weaknesses of the rotator cuff, the rigidity of the posterior capsule, and the subacromial bursa associated with crepitus:

- Phase 1: This phase consists of modifying the daily activities carried out by the subject in order to reduce their impact on shoulder pathology. Once the symptoms of the pathology decrease, the activity will be progressively resumed until normal levels of intensity are reached.

- Phase 2: The flexo-extension arch of the injured shoulder must be restored. To do this, static stretches of mild intensity are performed three times a week. Each stretch is performed to the point where the patient feels a pull against the stiffness of the shoulder without feeling pain. The duration of each stretch is $1 \mathrm{~min}$, investing a total of $30 \mathrm{~min}$ a day in the whole set of stretches.

- Phase 3: Recovery of muscle strength. Before beginning this phase, almost normal mobility should have been recovered. To recover muscle strength, internal and external rotation exercises as well as reinforcement with the arm against the side of the chest are performed. Loads are employed using free weights lower than $0.5 \mathrm{~kg}$ or elastic belts. A total of three sets of 8-10-12 repetitions are performed, which can be modified to adjust the intensity of the exercise.

- Phase 4: Global aerobic retraining. This phase is intended to restore the physical fitness of subjects due to the period of inactivity. It consists of performing 30-60 min of low-moderate intensity aerobic activity three times a week (walking, jogging, cycling, etc.). It is important that the exercises do not involve forced movements in the shoulder and scapula area to aggravate the pathology.

- Phase 5: Work or sport changes. In this last phase, the physiotherapist reviews the work and sports activity of the patient in order to modify movements that may be harmful to the shoulder joint. This phase aims to improve the technique and postural hygiene.

The educational program applied to Groups 1 and 3 is based on the standards that adults must adopt for developing properly activities and postural habits in their lifetime. The indications suggested 
by Matsen et al. [27] and Heyman et al. [28] were followed, which established correct posture habits in the workplace and at home concerning their sleeping habits, seats, footwear, or positions and habits they followed while performing physical activity.

The collection of data in the "PRE" phase was carried out during the month of January 2015, the intervention program was conducted during February to November 2015, and the data in the "POST" phase were collected in November 2015. Permission was obtained from the Ethics Committee for Research of the University of Santo Tomás de Chile (CE UST No80/2014).

\subsection{Statistical Analysis}

The participation rate was $80.40 \%$ with a total of 10 invalided questionnaires due to incorrect completion of the tests. For the statistical study of the parameters, the Shapiro-Wills test was first performed to establish the normality of the data. Once determined, the descriptive study was conducted. Frequencies, percentages, means, and standard deviation were aimed to describe all the variables. Moreover, the T-Test and Cohen's D were used in order to know the effect of the three intervention programs developed. It was carried out using SPSS 22.0 Software (IBM Corp, Armonk, NY, USA).

\section{Results}

The study found that $22(53.7 \%)$ participants had rotator cuff tendinopathies, while the remaining adults had similar numbers in other categories: seven (17.1\%) showed tendon rupture, four $(9.8 \%)$ had bursitis, four $(9.8 \%)$ had a frozen shoulder, and four (9.8\%) suffered subacromial impingement. In addition, subjects with a bad shoulder assessment by UCLA consisted of 27 (65.9\%) in the PRE-test, and $23(56.1 \%)$ in the POST-test. Five (12.2\%) respondents showed a good evaluation in PRE-test, while eight $(22.0 \%)$ showed a good evaluation in POST-test. Most of the participants had below 70 points with regard to health status in both the PRE-test $(68.32 \pm 16.74)$ and POST-test $(68.95 \pm 16.03)$ (Table 2).

Table 2. Descriptive study of the variables.

\begin{tabular}{|c|c|c|c|}
\hline Variables & Categories & \multicolumn{2}{|c|}{$\mathbf{N}(\%) / \mathrm{M} \pm \mathrm{SD}$} \\
\hline & Men & \multicolumn{2}{|c|}{$19(46.3 \%)$} \\
\hline Gender & Women & \multicolumn{2}{|c|}{$22(53.7 \%)$} \\
\hline & Rotator cuff tendinopathy & \multicolumn{2}{|c|}{$22(53.7 \%)$} \\
\hline & Tendon rupture & \multicolumn{2}{|c|}{$7(17.1 \%)$} \\
\hline Shoulder Pathology & Bursitis & \multicolumn{2}{|c|}{$4(9.8 \%)$} \\
\hline & Frozen shoulder & \multicolumn{2}{|c|}{$4(9.8 \%)$} \\
\hline & Sub acromial impingement & \multicolumn{2}{|c|}{$4(9.8 \%)$} \\
\hline & & PRE & POST \\
\hline \multirow{4}{*}{ UCLA Evaluation } & Excellent & $2(4.9 \%)$ & $1(2.4 \%)$ \\
\hline & Good & $5(12.2 \%)$ & $8(19.5 \%)$ \\
\hline & Regular & $7(17.1 \%)$ & $9(22.0 \%)$ \\
\hline & Bad & $27(65.9 \%)$ & $23(56.1 \%)$ \\
\hline EUROQOL & Health Status Score & $68.32 \pm 16.74$ & $68.95 \pm 16.03$ \\
\hline
\end{tabular}

Table 3 shows comparisons of the UCLA assessment and health status before and after the execution of the intervention program in the different groups. Statistically, differences were observed in the majority of experimental groups, except in Group 3 (subjects who received a postural education program). In the case of the control group, a decrease was observed in the score obtained by the UCLA scale $(14.30 \pm 5.47$ vs. $10.80 \pm 3.36)$ and by the health state $(62.70 \pm 15.21$ vs. $57.50 \pm 14.76)$, showing statistically significant differences in both cases $(p=0.016, p=0.026$, respectively).

Analyzing the experimental groups, the experimental Group 1 (participants who the intervention program based on the Jackins technique and the postural education program) improved in the UCLA 
shoulder evaluation $(27.10 \pm 7.29$ vs. $29.70 \pm 4.05)$ and the global health status $(76.40 \pm 7.51)$. vs. 82.60 \pm 5.77 ), revealing statistically significant differences in both cases ( $p=0.044, p=0.010$, respectively). In addition, the UCLA evaluation showed a medium effect size with a value for Cohen's D of $d=0.44$, while a high value for health status was obtained $(\mathrm{d}=0.92)$.

Experimental Group 2 (participants who only received the intervention program based on the Jackins technique) also improved in scores obtained in the post-tests for the UCLA scale (17.70 \pm 7.22 vs. $24.20 \pm 4.63)$ and health status $(66.50 \pm 22.36$ vs. $74.50 \pm 16.74)$, with statistically significant differences in both cases ( $p=0.001, p=0.013$, respectively). Similarly, the UCLA evaluation showed a high effect size with a value for the Cohen $D$ of $d=0.98$, while a medium value for health status was obtained $(\mathrm{d}=0.40)$.

Table 3. Comparison between PRE and POST, with regard to the UCLA evaluation and health status in different experimental groups.

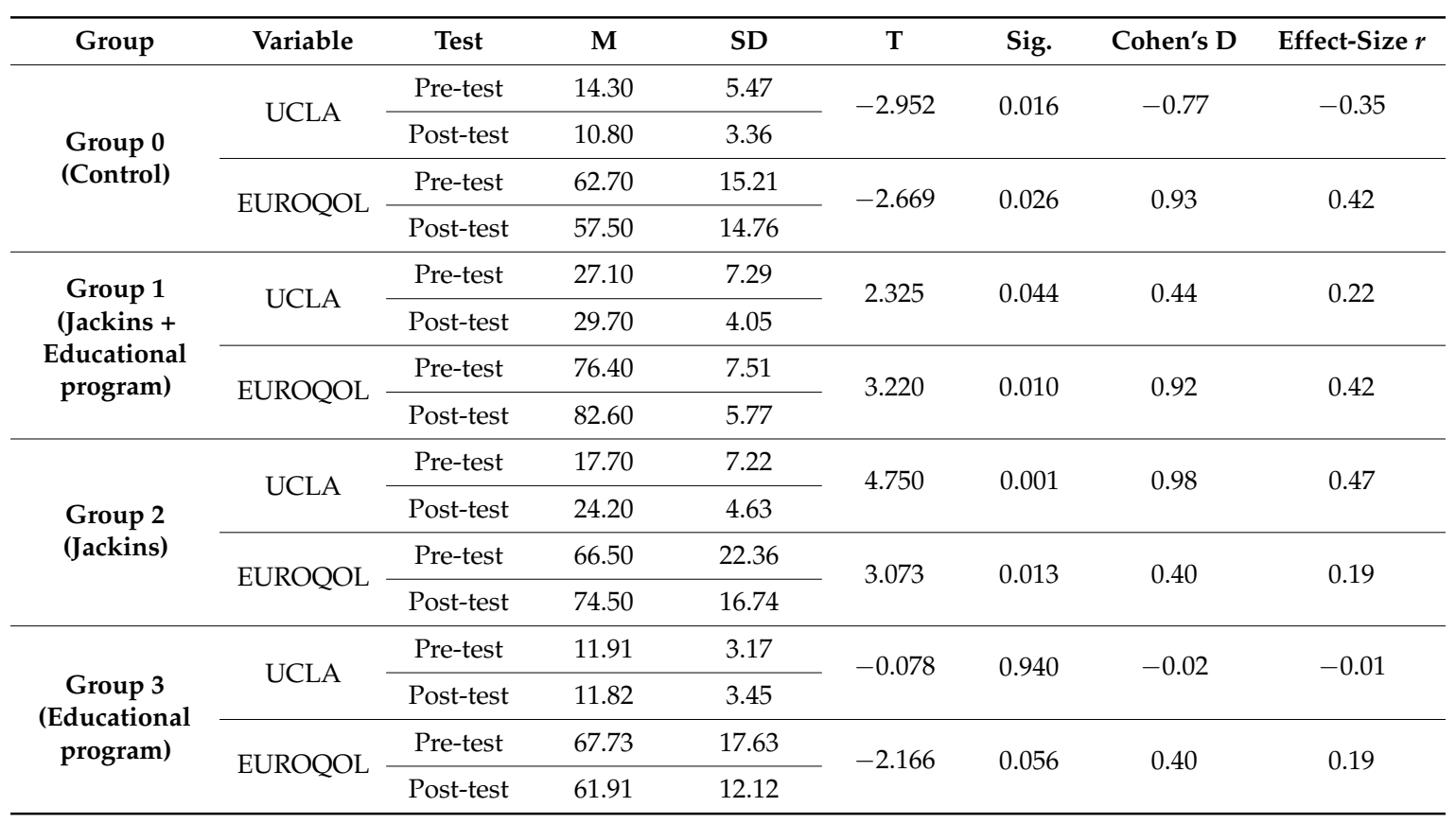

\section{Discussion}

This research study analyzed the effect of an intervention program based on physical activity and postural education in a sample of adults from Chile with shoulder pathology. The program lasted six months, working with three experimental groups in order to learn the effect of Jackins technique, postural education, and the combined effect of both actions. In particular, it was aimed toward the improvement of the perceived health status and the UCLA evaluation of shoulder. Other similar studies carried out by this study are similar to other studies performed in other adult populations with dysfunctional shoulders [29-31], where the noninvasive method is currently the most frequently used in the shoulder abnormality diagnosis and treatment.

Considering the prevalence of the shoulder pathologies analyzed, it was found that more than half of respondents had rotator cuff tendinopathy, implying that this population is similar to other American and worldwide populations [30]. Following this information, we must consider that this dysfunction started with a bad UCLA evaluation in most of the subjects analyzed. These data imply dissatisfaction and painful processes in adults who suffer from shoulder pathology, as was shown by Ludewig et al. [21], Bulgen et al. [29], and Dias et al. [30]. For this reason, the values shown for the EuroQol scale are below 70 points in the present research, which is associated with a worse state of health $[25,31]$. 
In this sense, Abdulla et al. [32] highlighted that shoulder injuries in the United States are the third largest contributor to the total compensation costs of workers (after back injuries and knee). This joint pain is usually persistent, producing a high disability in work activity and daily life. Furthermore, it is a major burden on health resources in Spain and leads to lost productivity due to absenteeism, as shown by Cadogan et al. [33]. For these reasons, it is essential to develop intervention programs aimed to prevent these kind of pathologies as well as treat them [34].

Health status was decreased in the sample studied, similar to the results obtained Pellicer et al. [35] for middle-aged people. In line with these findings, Reijneveld et al. [36] included the biological and behavioral impacts caused by shoulder pain with consequent alteration in sleep, which affects the well-being of patients who obtain values lower than normal in questionnaires such as the SF-36. This type of pathology usually affects the lifestyle of adults and older adults, decreasing their functionality and autonomy [37,38]. In addition, Andersen et al. [39] developed a shoulder function training primarily focused on the serratus anterior and lower trapezius muscle. This training was performed for 20 min three times a week over 10 weeks, showing how the practice of physical exercise can decrease the pain associated with musculoskeletal problems of the shoulder and neck.

Considering the intervention program developed, the Jackins program resulted in improvements in shoulder evaluation. Thus, the practice of adequate physical exercise (over six months) produced an improvement in shoulder disability and health status. According to the study developed by Granviken et al. [40], a prescription of therapeutic exercise at home in patients with subacromial syndrome was associated with an increase of $30-40 \%$ incorporation of these patients to their work activities. Moreover, Brox et al. [41] justified these favorable results by basing them on a decrease of emotional distress and pain which are generated by the shoulder pathology suffered. Similarly, Ludewig et al. [21] found greater satisfaction among participants who performed rehabilitation programs compared with patients who were not involved in the therapeutic exercise program for treating the subacromial syndrome.

In the present study, the postural education program was insufficient to achieve shoulder rehabilitation. This is due to the fact that these types of interventions are useful in the prevention of injuries but are ineffective for the recovery of pathologies that are already established [42,43]. Nevertheless, the rehabilitation program based on physical exercise was effective, as it produced adaptations in the soft tissues, which accelerated the recovery process and decreased the perception of pain. This can be explained through the improvement of blood irrigation produced by exercise-favoring tissue nutrition and oxygenation, the maintenance of joint range thanks to programmed movement, or the strengthening of ligaments and tendons, which reduces joint instability [44,45].

Some clinical implications can be extracted from the present research in relation to adults suffering from shoulder patholohy. The actions linked to postural education are not adequate for the improvement of shoulder pain. However, they can be useful as a means of prevention in the face of this type of problem. On the other hand, the realization of physical exercise is beneficial for improving the functionality of the joint and reducing pain. A first phase of immobilization is recommended, followed by a second phase in which basic flexo-extension stretches are performed statically, with durations of $30 \mathrm{~s}$ per action. Once the range of movement suitable for the glenohumeral joint has been recovered, strengthening of the peripheral musculature is recommended through exercises with light loads $(0.5 \mathrm{~kg})$ and moderate intensity. Finally, it is important to combine these actions with aerobic training that allows the recovery of the physical fitness lost during the period of immobility.

In the development of this research, we have identified some limitations, such as a small number of participants. In addition, we have not performed an extension of the study to other populations, which would offer a wider perspective. Moreover, another limitation is the controlled variables, since the body composition of the subjects or whether they suffered from other pathologies were not considered. In future research, it would be interesting to reproduce this study with a greater number of participants, as well as subjects of different age groups and pathologies. It would also be interesting to 
include more variables on the health status of the respondents, as well as other psychological variables that could be related to the perception of pain, such as resilience.

\section{Conclusions}

Considering the research question, we can establish that an intervention program based on physical activity and postural education can improve the UCLA evaluation of the shoulder and the health status of adults. Nevertheless, these two actions have a different effect. Therefore, we need to make certain points about the hypothesis:

- Hypothesis 1 (H1) was partially fulfilled, since the intervention based on physical activity improved UCLA evaluation and health status. Nevertheless, the program based on postural education did not improve these variables.

- Hypothesis 2 (H2) was not fulfilled. The intervention program based on physical activity was the most effective, followed by the intervention program based on physical activity and postural education.

As a main conclusion, we can establish that the participants who received the program based on physical activity (Jackins technique) experienced a higher effect size in the shoulder evaluation than those who received the program based on physical activity and postural education. On the contrary, this last group received the highest score in the perceived health status. The intervention only based on postural education did not improve the shoulder pathology and the perception of the perceived health state.

Author Contributions: R.C.-C., F.Z.-O., and M.C.-S. conceived the hypothesis of this study; F.Z.-O., M.C.-S., C.C.-B., M.C.N.-Z., and M.F.-S. participated in data collection; R.C.-C. and M.C.-S. analyzed the data; All authors contributed to data interpretation of statistical analysis. R.C.-C., C.C.-B., and M.C.-S wrote the paper with significant input from F.Z.-O.; All authors read and approved the final manuscript.

Funding: This research received no external funding.

Conflicts of Interest: The authors declare no conflict of interest.

\section{References}

1. Frau-Escales, P.; Langa-Revert, Y.; Querol-Fuentes, F.; Mora-Amérigo, E.; Such-Sanz, A. Shoulder musculoskeletal disorders in primary care. A cross-sectional study in a health care center of the Valencia Health Care Agency. Fisioter 2013, 35, 10-17. [CrossRef]

2. Cadogan, A.; Laslett, M.; Hing, W.A.; McNair, P.J.; Coates, M.H. A prospective study of shoulder pain in primary care: Prevalence of imaged pathology and response to guided diagnostic blocks. BMC Musculoskelet. Disord. 2011, 12, 119. [CrossRef] [PubMed]

3. Razmjou, D.; Boljanovic, D.; Lincoln, S.; Geddes, C.; Macritchie, I.; Virdo-Cristello, C.; Richards, R. Examining outcome of early physician specialist assessment in injured workers with shoulder complaints. BMC Musculoskelet. Disord. 2015, 16, 32. [CrossRef]

4. Sharma, S.; Bærheim, A.; Kvåle, A. Passive range of motion in patients with adhesive shoulder capsulitis, an intertester reliability study over eight weeks. BMC Musculoskelet. Disord. 2015, 16, 37. [CrossRef] [PubMed]

5. Hegedus, E.J.; Cook, C.; Lewis, J.; Wright, A.; Park, J.Y. Combining orthopedic special tests to improve diagnosis of shoulder pathology. Phys. Ther. Sport 2015, 16, 87-92. [CrossRef] [PubMed]

6. Circi, E.; Okur, S.C.; Aksu, O.; Mumcuoglu, E.; Tuzuner, T.; Caglar, N. The effectiveness of extracorporeal shockwave treatment in subacromial impingement syndrome and its relation with acromion morphology. Acta Orthop. Traumatol. Turc. 2018, 52, 17-21. [CrossRef] [PubMed]

7. Carbone, S.; Postacchini, R.; Gumina, S. Scapular dyskinesis and SICK syndrome in patients with a chronic type III acromioclavicular dislocation. Results of rehabilitation. Knee Surg. Sports Traumatol. Arthrosc. 2015, 23, 1473-1480. [CrossRef] [PubMed]

8. Waterman, B.; Cameron, K.; Hsiao, M.; Langston, J.; Clark, N.; Owens, B. Trends in the diagnosis of SLAP lesions in the US military. Knee Surg. Sports Traumatol. Arthrosc. 2015, 23, 1453-1459. [CrossRef] [PubMed] 
9. Magarey, M.E.; Jones, M.A.; Cook, C.E.; Hayes, M.G. Does physiotherapy diagnosis of shoulder pathology compare to arthroscopic findings? Br. J. Sports Med. 2016, 50, 1151-1157. [CrossRef] [PubMed]

10. Kappe, T.; Knappe, K.; Elsharkawi, M.; Reichel, H.; Cakir, B. Predictive value of preoperative clinical examination for subacromial decompression in impingement syndrome. Knee Surg. Sports Traumatol. Arthrosc. 2015, 23, 443-448. [CrossRef] [PubMed]

11. Sole, G.; Osborne, H.; Wassinger, C. The effect of experimentally-induced subacromial pain on proprioception. Man. Ther. 2015, 20, 166-170. [CrossRef] [PubMed]

12. Zurita, F.; Ruiz, L.; Martínez, A.; Fernández, M.; Rodríguez, C.; López, R. Hiperlaxity ligamentous (Beighton test) in the 8 to 12 years of age school population in the province of Granada. Reumatol. Clín. 2010, 6, 5-10. [CrossRef] [PubMed]

13. Hultenheim, I.; Gunnarsson, A.; Svantesson, U.; Styf, J.; Karlsson, J. Early activation or a more protective regime after arthroscopic subacromial decompression-a description of clinical changes with two different physiotherapy treatment protocols-A prospective, randomized pilot study with a two-year follow-up. Clin. Rehabil. 2008, 22, 951-965. [CrossRef] [PubMed]

14. Macías-Hernández, S.; Pérez-Ramírez, L. Eccentric strength training for the rotator cuff tendinopathies with subacromial impingement. Current evidence. Cirugía y Cirujanos 2015, 83, 74-80. [CrossRef]

15. Badicu, G. Physical Activity and Sleep Quality in Students of the Faculty of Physical Education and Sport of Brasov, Romania. Sustainability 2018, 10, 2410. [CrossRef]

16. O'Kane, J.; Jackins, S.; Sidles, J.; Smith, K.; Matsen, F. Simple home program for frozen shoulder to improve patient's assessment of shoulder function and health status. J. Am. Board Fam. Pract. 1999, 12, $270-277$. [CrossRef]

17. Badicu, G. Values of the body mass index of adolescents from Romania reported to the number for hours of physical education practiced. Pedag. Psychol. Med.-Biol. Probl. Phys. Train Sports 2018, 22, 177-183. [CrossRef]

18. Navarro-Zurita, C. Effects of a Program based on Postural Education and Training of the Shoulder Muscles: Educational Guidelines for the Prevention of the Evolutionary Course of the Subacromial Syndrome. Ph.D. Thesis, University of Granada, Granada, Spain, 2016.

19. López, G.F.; Nicolás, J.; Díaz, A. Effects of a program through vigorous-intensity physical activity on blood pressure and heart rate of 10-11-year-old school children. J. Sport Health Res. 2018, 10, 13-24.

20. Michener, L.; Walsworth, M.; Burnet, E. Effectiveness of rehabilitation for patients with subacromial impingement síndrome: A systematic review. J. Hand Ther. 2004, 17, 152-164. [CrossRef]

21. Ludewig, P.M.; Borstad, J.D. Effects of a home exercise programme on shoulder pain and functional status in construction workers. Occup. Environ. Med. 2003, 60, 841-849. [CrossRef]

22. Provencher, M.; Bhatia, S.; Ghodadra, N.S.; Grumet, R.C.; Bach, B.R., Jr.; Dewing, L.C.B.; LeClere, L.L.; Romeo, A.A. Recurrent shoulder instability: Current concepts for evaluation and management of glenoid bone loss. J. Bone Jt. Surg. 2010, 92, 133-151. [CrossRef] [PubMed]

23. Pepe, M.; Rodosky, M. Non-operative treatment of common shoulder injuries in athletes. Sports Med. Arthrosc. Rev. 2001, 9, 96-104. [CrossRef]

24. Christiansen, D.; Falla, D.; Frost, P.; Frich, L.; Svendsen, S. Physiotherapy after subacromial descompression surgery: Development of a standardised exercise intervention. Physiotherapy 2015, 101, 327-339. [CrossRef] [PubMed]

25. Amstutz, H.C.; Sew, A.L.; Clarke, I.C. UCLA anatomic total shoulder arthroplasty. Clin. Orthop. 1981, 155, 7-20. [CrossRef]

26. Herdman, M.; Badia, X.; Berra, S. The EuroQol-5D: A simple alternative for measuring the quality of life related to health in primary care. Aten. Prim. 2001, 28, 425-429. [CrossRef]

27. Matsen, R. Shoulder; Marban: Madrid, Spain, 2006.

28. Heyman, E.; Dekel, H. Ergonomics for children: An educational program for elementary school. Work 2009, 32, 261-265. [CrossRef]

29. Bulgen, D.Y.; Binder, A.I.; Hazleman, B.L.; Dutton, J.; Roberts, S. Frozen shoulder: Prospective clinical study with an evaluation of three treatment regimens. Ann. Rheum. Dis. 1984, 43, 353-360. [CrossRef]

30. Dias, R.; Cutts, S.; Massoud, S. Frozen shoulder. BMJ 2005, 331, 1453. [CrossRef]

31. Cáceres-Sánchez, L.; Mesa-Mateo, A.; Barrionuevo-Sánchez, F.J.; García-Benítez, B.; Expósito-Triano, S. Total inverted shoulder arthroplasty. Evaluation of clinical outcomes and complications after a series of 52 cases. Rev. Esp. Cirug. Ortop. Traumatol. 2015, 59, 439-446. [CrossRef] 
32. Abdulla, S.; Southerst, D.; Côté, P.; Shearer, H.; Sutton, D.; Randhawa, K.; Varatharajan, S. Is exercise effective for the menagement of subacromial impingement síndrome and other soft tissue injuries of the shoulder? A systematic review by the Ontario protocol for traffic injury management (OPTIMA) collaboration. Man. Ther. 2015, 20, 646-656. [CrossRef]

33. Cadogan, A.; Mc Nair, P.; Laslett, M.; Hing, W.; Taylor, S. Diagnostic accuracy of clinical examination features for identifying large rotator cuff tears in primary health care. J. Man. Manip. Ther. 2013, 21, 148-159. [CrossRef] [PubMed]

34. Zurita, F.; Espejo, T.; Cofré, C.; Martínez, A.; Castro, M.; Chacón, R. Influence of physical activity on resilience in adults with shoulder pain. Sport TK 2016, 5, 53-58. [CrossRef]

35. Pellicer, V.; Gomar, F. Evaluation of the Treatment of Degenerative Tendinopathy of the Rotator Cuff of the Shoulder by Ultrasound-Guided Infiltrations of Platelet-Rich Plasma. Ph.D. Thesis, University of Valencia, Valencia, Spain, 2015.

36. Reijneveld, E.A.; Noten, S.; Michener, L.A.; Cools, A.; Struyf, F. Clinical outcomes of a scapular-focused treatment in patients with subacromial pain syndrome: A systematic review. Br. J. Sports Med. 2017, 51, 436-441. [CrossRef] [PubMed]

37. Herrera, E.; Pablos, A.; Chiva-Bartoll, O.; Pablos, C. Effects of physical activity on perceived health and physical condition on older adults. J. Sport Health Res. 2017, 9, 27-40.

38. Chacón, R.; Chacón, F.; Zurita, F.; Cachón, J.; Zagalaz, M.L.; Chinchilla, J.J. Characterization of motivation and type of physical-sport practice in adults through COMPASS profiles. J. Hum. Sport Exerc. 2018, 13, 161-173. [CrossRef]

39. Andersen, C.H.; Andersen, L.L.; Mortensen, O.S.; Zebis, M.K.; Sjøgaard, G. Protocol for shoulder function training reducing musculoskeletal pain in shoulder and neck: A randomized controlled trial. BMC Musculoskelet. Disord. 2011, 12, 14. [CrossRef] [PubMed]

40. Granviken, F.; Vasseljen, O. Home exercises and supervised exercises are similarly effective for people with subacromial impingement: A randomised trial. J. Physiother. 2015, 61, 135-141. [CrossRef] [PubMed]

41. Brox, J.; Gjengedal, E.; Uppheim, G.; Bohmer, A.; Brevik, J.; Ljunggren, A.; Staff, P. Arthroscopic surgery versus supervised exercises in patients with rotator cuff disease (stage II impingement síndrome): A prospective, randomized, controlled study in 125 patients with a $2 \frac{1}{2}$ year follow up. J. Shoulder Elbow Surg. 1999, 8, 102-111. [CrossRef]

42. Hanratty, C.E.; Kerr, D.P.; Wilson, I.M.; McCracken, M.; Sim, J.; Basford, J.R.; McVeigh, J.G. Physical therapists' perceptions and use of exercise in the management of subacromial shoulder impingement syndrome: Focus Group Study. Phys. Ther. 2016, 96, 1354-1363. [CrossRef]

43. Coito, J.; Oliveira, R.; Melo, F. Effects of a Neuromotor Reeducation Program on Pos-tural Control and Musculoskeletal Injury Incidence of Amateur Football Players. J. Orthop. Res. Ther. 2016, 2, 27-33.

44. Sánchez-García, C.; López-Sánchez, G.F.; González-Carcelén, C.M.; Ibáñez-Ortega, E.J.; Díaz-Suarez, A. Physical fitness and body image of Sports Science Students. ESHPA Educ. Sport Health Phys. Act. 2018, 2, 92-104.

45. Kisner, C.; Colby, L.A.; Borstad, J. Therapeutic Exercise: Foundations and Techniques; Fa Davis: Philadelphia, PA, USA, 2017.

(c) 2018 by the authors. Licensee MDPI, Basel, Switzerland. This article is an open access article distributed under the terms and conditions of the Creative Commons Attribution (CC BY) license (http:// creativecommons.org/licenses/by/4.0/). 